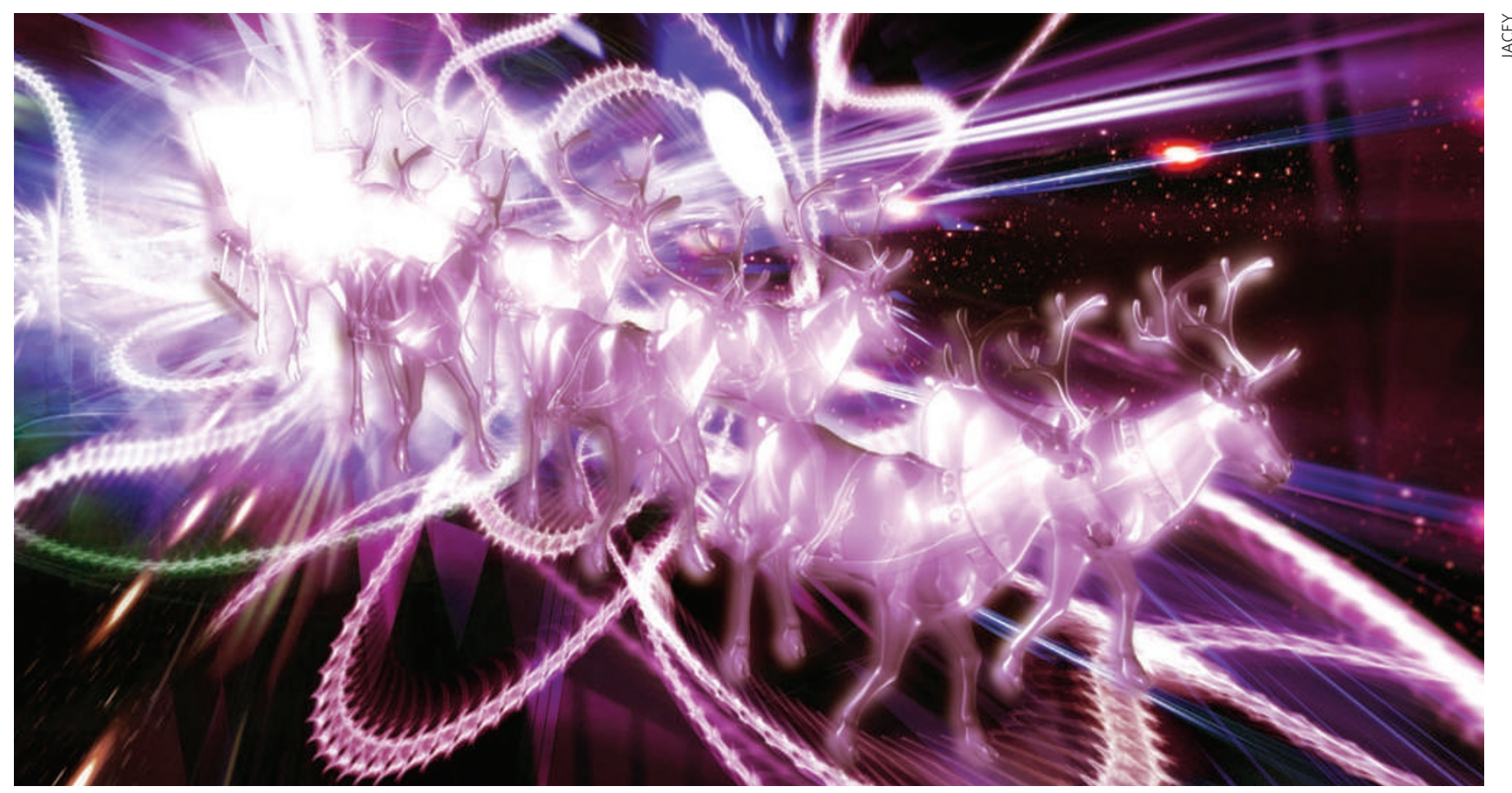

\title{
Harnessing the brane-deer
}

\section{It's a constant worry.}

\section{Robert Billing}

"Fortunately," said the young squadron leader as the Land Rover bumped across the moonlit airfield, tyres hissing through the sprinkling of snow, "all eight reindeer managed to eject before it hit the ground, or we'd be scraping diced venison off the runway."

"Reindeer?" I asked. "I'm a physics teacher, not a zoo keeper."

"You'll see." He slalomed the vehicle between the blue edge lights and onto the runway. "The snow makes it easier to work out what happened. The tracks start here." He pointed to two narrow grooves in the snow. "The old chap made a good show of getting it down. It must have been handling like a brick but he managed to hit the runway and stop it more or less on the centre line."

The headlights picked out something scarlet in the distance. Something with runners. Something piled with sacks full of parcels. Beside it stood a rotund man in red, his fur-trimmed hood thrown back to reveal one of those big, greenish headsets that airline pilots wear, the microphone boom just in front of his snowy beard.

"You're having me on!" I complained, but my companion carried on driving.

"I wish I was." He parked the Land Rover alongside the sleigh. "It would be a lot easier than admitting that Father Christmas has just made a forced landing on an RAF station."
"So what do you want me to do?"

"Well, we've got this problem. We'd like to fix the sleigh and let him take off again but..." He trailed off into an embarrassed silence.

"But what?" I was cold, tired and in no mood to play games.

"We have absolutely no idea how it manages to stay up at all. Aerodynamically it's nonsense, there is no way that a reindeer can develop enough power to lift its own weight, let alone pull a sleigh off the ground."

I agreed. One particularly tubby specimen wandered up out of the darkness. I opened my window and gave it a peppermint from the packet in my coat pocket. For a moment my fingers were illuminated by a diffuse red glow.

"Did I just see its nose light up? No, don't tell me. Rudolf?"

The reindeer seemed to nod.

"The other problem," my companion said, "is the flight plan."

"What about it?"

"It's on a hard drive built into the sleigh's dashboard. There are several billion sets of coordinates, and a list of presents against each one."

"So?"

"To start and stop that many times in one night would mean accelerations of thousands of gees. And that would mean ..."

"Diced venison?"

"Exactly. We think the two things are related. Whatever lets reindeer fly lets him survive forces that would kill a human pilot in less than a second. Just think what that would mean..."

"Oh no! I am not doing this. I am not helping you convert Santa's sleigh into the ultimate fighter aircraft."

"For Queen and country?"

"No."

"A lot of money?"

"No." He paused, assessing my weak spot.

"You must realize that whoever finds out how this is done will revolutionize the world's transport systems, maybe even fix global warming, make cheap space flight possible..."

"Still no."

"And quite possibly," he paused, spinning out the sentence, "come to the attention of a certain prize committee..."

I swallowed hard. When I gave up university life for teaching I'd abandoned all hope of academic recognition. Except that if this worked I might just ...

It couldn't happen.

It might.

I'd look good in a dinner jacket in Stockholm.

Iopened the door and slid out of the Land Rover, my feet crunching on the thin snow. Santa was peering into an open inspection cover at the front of the sleigh, prodding at the circuit boards inside with what looked like a long, thin, tree decoration connected to a portable logic analyser.

"Channel 17 is good," he said into the 
headset. "It's showing a live cat." He paused. "Can you get one of the elves from the maths department? I want to know what will happen if I open it." Then he took off his headset and beamed at me. "Merry Christmas! Have you come to help?"

"I hope so. Can you tell me what happened?"

He paused for a moment, a worried smile on his face. "We'd taken off from Lapland as normal. About ten seconds into the climb-out I started getting high temperatures on three and four." He tapped the row of gauges built in to the sleigh's dashboard. The third and fourth were labelled 'Prancer' and 'Vixen.' "I aborted the equivalence at once. About three seconds later I lost power completely and made a forced landing."

I was calculating in my head.

"Lapland to Kent in 13 seconds is around 100 miles per second, way beyond escape velocity. You don't need aerodynamics, do you? It's just raw speed that makes it fly." Santa nodded. "Although how you manage to push through the atmosphere at Mach 500 without burning up defeats me."

The old man just smiled. "It is a mystery if you don't understand."

I got up onto the sleigh, sat on the bench seat and studied the instruments. There was a little rectangular screen showing a globe of the Earth, divided by lines of latitude and longitude, the spaces between them a chequer-board of light and dark patches. Two digital readouts were labelled $\Lambda_{\mathrm{EW}}$ and $\Lambda_{\mathrm{NS}}$. Both showed zero. A little farther along was another display simply labelled ' $h$ ', and next to it was an impressive red handle. Almost automatically I wound my fingers around it, ready to pull. Santa jumped. For a moment there was a flash of real terror in his eyes, then he was jolly again. Whatever it was, I'd hit it. Lambda, $h$ and a pattern tessellating the planet, this was the key to the whole thing. Pulling the big red lever could have disastrous consequences, only it wasn't working.

Which was why the sleigh was on the ground.

I sat back. When the sleigh was in what Santa called 'the equivalence', it whistled along, slipping through the atmosphere at speeds that would fill NASA with envy. The only thing that could overtake it was light.

The secret had to be in the reindeer, or rather in the composite of engineering and biology that sleigh and reindeer made together. Perhaps some weird twist of evolution had produced a beast that existed partly on another brane, one with a much bigger value of Planck's constant. What if Santa had found some way to harness the multiversal nature of the reindeer, to mould a subtle and unstable biological process into useful technology?

There were about 15 digits on the ' $h$ ' display, although only a single zero glowed cheerily at the right-hand end.

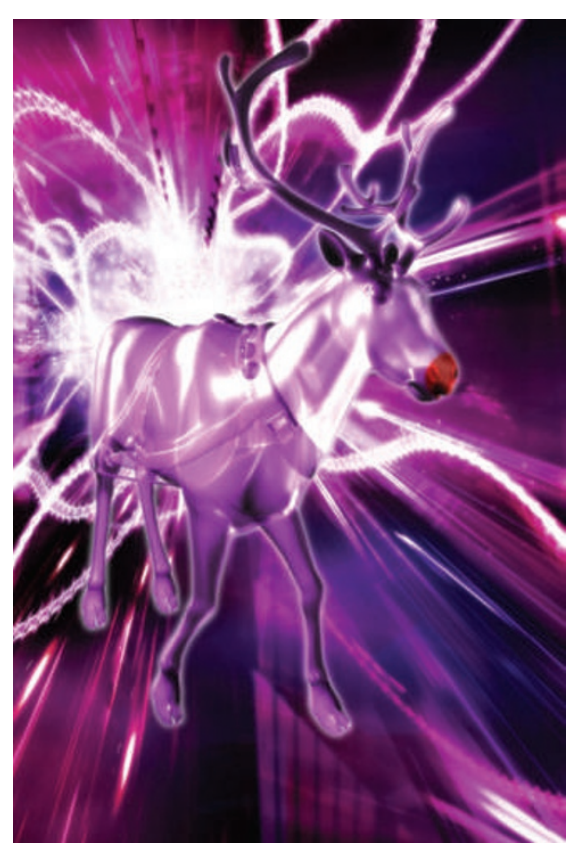

No, it couldn't be ...

It was. The big red lever changed the value of Planck's constant for the sleigh. Changed it so that the sleigh could convert into a single photon. A photon with a wavelength of a few metres. I tried to visualize the effect of quantum mechanics happening on a macroscopic scale, of the sleigh having a definite wavelength.

So that was what the lambda gauges measured, although I couldn't see why the north-south and east-west wavelengths were different. The sleigh would become a standing wave, rather like an electron orbit, all around Earth. No, all over Earth.

The last section of the puzzle clicked into place. The pattern on the picture of Earth was a set of spherical harmonics, the standing wave that the sleigh became when the red handle was pulled. So that was how the old chap did it. He didn't have to rush around the planet, just convert into a standing wave that was everywhere on Earth simultaneously, and wait for the midnight line to pass right around the world under him. At any time there was a very small probability of his being in any particular chimney, but averaged over the whole night he was everywhere, once.

So why had it stopped working? What had disrupted the delicate processes inside two of the reindeer and brought the sleigh crashing back into our world?

Rudolf wandered towards the sleigh, nose flickering like a disco in an LED factory, a silly grin on his face. Suddenly I had an idea.

"Santa! The two reindeer that had high temperatures, are they boys or girls?"

Santa laughed. "Everyone knows that Vixen is female, but the books are wrong about Prancer. She's a girl as well."

There's one thing that can happen to a female mammal that plays Old Harry with delicate internal processes. I turned to the squadron leader. "We need a veterinary surgeon, now."

Twenty minutes later it was all over. Prancer and Vixen had provided positive pregnancy tests; Blitzen was being awkward about letting us have a sample.

"Rudolf!" snapped Santa, "I've told you before!"

Rudolf's nose flared an embarrassed scarlet. Santa unwrapped a parcel and pulled out a slide rule. "I'll take off on reduced power and follow the great circle back to Lapland. I should get home before they overheat again. Then I'll swap Vixen and Prancer for Robbie and Rusty. The presents may be a few hours late but they'll still get there. Thanks, and Merry Christmas."

He whistled, and the reindeer lined up ready for the harness. Then he was on the seat with the reins in his hands, Rudolf's nose started to flash like an anti-collision beacon and the sleigh accelerated down the runway. I saw one fur-gloved hand reach out to pull the big red lever, then there was a flash, a rush of wind and the sleigh was a vanishing dot on the horizon.

That's why, every Christmas, I leave a packet of peppermints, a glass of sherry and a letter by the fireplace.

"Dear Santa, for Christmas I'd really like one present. How do reindeer change the value of Planck's constant?"

And every year I receive a photograph of Rudolf's growing family.

Robert Billing records his gratitude to the late Kenneth Pascoe, of St John's College, Cambridge, who set a supervision question that, years later, triggered the idea for this story.

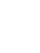

.

